\title{
Controlling the kinetics of interferon transgene expression for improved gene therapy.
}

$\operatorname{AUTHOR}(\mathrm{S})$ :

Watcharanurak, Kanitta; Nishikawa, Makiya;

Takahashi, Yuki; Takakura, Yoshinobu

\section{CITATION:}

Watcharanurak, Kanitta ...[et al]. Controlling the kinetics of interferon transgene expression for improved gene therapy.. Journal of drug targeting 2012, 20(9): 764-769

\section{ISSUE DATE:}

2012-11

URL:

http://hdl.handle.net/2433/182930

\section{RIGHT:}

(C) 2012 Informa UK, Ltd.; This is not the published version. Please cite only the published version.; この論文は出版社版でありません。引用の 際には出版社版をご確認ご利用ください。 
Controlling the kinetics of interferon transgene expression for improved gene therapy Kanitta Watcharanurak, Makiya Nishikawa, Yuki Takahashi, and Yoshinobu Takakura Department of Biopharmaceutics and Drug Metabolism, Graduate School of Pharmaceutical Sciences, Kyoto University, Kyoto, Japan

Address for Correspondence:

Yoshinobu Takakura, PhD, Department of Biopharmaceutics and Drug Metabolism, Graduate School of Pharmaceutical Sciences, Kyoto University, 46-29 Yoshidashimoadachicho, Sakyo-ku, Kyoto 606-8501, Japan.

E-mail: takakura@pharm.kyoto-u.ac.jp

Keywords: non-viral vector, plasmid DNA, CpG motifs, plasmid backbone, promoter, enhancer 


\begin{abstract}
s
Interferon (IFN) gene based therapy has been studied for the treatment of many diseases such as viral infections, cancer and allergic diseases. Non-viral vectors, like plasmid DNA, are promising ways for delivering IFN genes, because of their low immunogenicity and toxicity compared with viral vectors. Potent therapeutic effects of IFN gene transfer will depend on the level and duration of transgene expression after in vivo administration. Therefore, controlling the kinetics of transgene expression of IFNs is a rational approach for improved gene therapy. The design and optimization of plasmid vectors, as well as their route/method of administration, is the key to obtaining high and persistent transgene expression. In this review, we aim to present experimental evidence about the relationships among the properties of plasmid vectors expressing IFNs, the kinetics of transgene expression, and therapeutic effects as well as safety issues.
\end{abstract}


Introduction

Interferon (IFN) belongs to a family of cytokines, classified into three types based on the receptors with which they interact to initiate signal transduction. Type I IFN consists of many IFN subtypes including IFN- $\alpha$ and IFN- $\beta$. Type I IFNs signal through an IFN- $\alpha$ receptor complex. IFN- $\gamma$ is the only IFN designated as a Type II IFN. IFN- $\gamma$ binds to an IFN- $\gamma$ receptor complex. The last and newest subgroup of IFNs, type III IFN, is IFN- $\lambda$. IFN- $\lambda$ signals through a receptor complex consisting of IFN- $\lambda$ receptor 1 and Interleukin-10 receptor 2. All types of IFNs have been shown to exert immunomodulatory, antiviral and antiproliferative effects. IFNs have been extensively studied as a treatment for many diseases, such as viral infections, allergic diseases and cancer. However, the success of IFN-based therapy in clinical practice is limited probably because of the short in vivo half-life of IFN. Therefore, IFN gene transfer has been considered to be a promising alternative to overcome this hurdle as, theoretically, it should be able to supply IFN for a long period of time (Platanias, 2005, Sadler and Williams, 2008, Bracarda et al., 2010, Kalanjeri and Sterman, 2012).

Gene therapy is defined as the transfer of a gene of interest, such as a cytokine or an antigen, into the body to treat diseases. For over two decades since the first clinical trial of gene therapy in the late 1980s (Edelstein et al., 2007), gene therapy has shown great promise in treating a variety of diseases, such as cancer, cardiovascular diseases and inherited diseases. Gene transfer can be performed using vectors, which are generally categorized as viral and non-viral. Despite their high transfection efficacy, viral vectors are generally associated with serious toxicities, high immunogenicity and a limitation in the size of the transgenes incorporated into the vector. Therefore, non-viral vectors, or non-viral gene delivery systems are very attractive alternatives because of their low toxicity, low immunogenicity, and ease of 
preparation without any limitation of DNA loading capacity. However, the main obstacle of non-viral vectors is the low and transient transgene expression, which prevents non-viral vectors from exerting efficient therapeutic effects (Kay, 2011, Li and Huang, 2007). To achieve efficient gene therapy, the improvement of plasmid DNA together with the efficient route/administration methods should be optimized. This review provides an overview on current non-viral vectors delivery methods, and summarizes the general ideas behind plasmid DNA modification for controlling the kinetics of transgene expression and some approaches that have been applied for IFN gene therapy in preclinical models. 
1. Non-viral vectors delivery methods

Several biological barriers obstruct the efficient delivery of plasmid DNA into target cells. Once plasmid DNA enters into the systemic circulation, it would be recognized by immune responses or interacts with biological components. After escaping from the extracellular matrix and reaches the target cell, plasmid DNA need to across the cell membrane and then import to the nucleus for transcription-translation process. The route/method of administration determines the number of barriers that should be overcome for successful in vivo gene transfer using plasmid DNA (Nishikawa and Huang, 2001, Escoffre et al., 2010). Many advanced technologies have been developed to deliver plasmid DNA into target cells, have been used and have been reviewed by many experts in details (Nishikawa and Huang, 2001, Nishikawa and Hashida, 2002, Al-Dosari and Gao, 2009, Mehier-Humbert and Guy, 2005, Escoffre et al., 2010, Kamimura et al., 2011). The latest gene therapy clinical trial data indicate that the most popular non-viral system used in clinical trial is naked DNA (18.5\% of all trials), followed by cationic lipid/DNA complexes (6\% of all trials) (Edelstein et al., 2004, Edelstein et al., 2007, Edelstein, 2012b). This section provides a brief summary of common non-viral gene delivery methods, which are categorized into physical and chemical approaches.

\subsection{Physical methods}

The physical approaches include the simple injection of naked plasmid DNA and the application of physical or electrical forces to increase cell permeability via the formation of transient pores in the plasma membrane. The advantages of this method are the simplicity and safety issue. Physical approaches are generally well tolerated.

\subsubsection{Naked plasmid DNA injection}


This is the simplest method to deliver plasmid DNA by injection of naked plasmid DNA into local tissues or systemic circulation. The number of clinical trials using naked plasmid DNA has increased from 14\% in 2004 to $18.5 \%$ in 2012 (Edelstein et al., 2004, Edelstein et al., 2007, Edelstein, 2012b). Wolff et al. was the first that reported in vivo plasmid DNA transfection by direct injection of naked plasmid DNA into mouse muscle (Wolff et al., 1990). In addition to intramuscular injection, efficient transgene expression could also be achieved by direct injection of plasmid DNA into other tissues such as skin (Choate and Khavari, 1997), intrathecal space (Hughes et al., 2009) and tumors (Nomura et al., 1997).

\subsubsection{Hydrodynamic injection}

Hydrodynamic based gene transfer is carried out by a high-speed intravenous injection of naked plasmid DNA with a large-volume of solution. The high pressure induced by hydrodynamic injection leads to a transient enhanced membrane permeability of hepatocytes, which allows the transfection of plasmid DNA (Zhang et al., 2004). This procedure has been widely used as the most convenient and efficient method for in vivo gene delivery to rodents. The hydrodynamic injection is also applied in large animals using a balloon catheter (Eastman et al., 2002) or computer-assisted device (Suda et al., 2008). This suggests that the hydrodynamic injection method is feasible for clinical application in the future.

\subsubsection{Gene gun}

Gene gun delivery, also known as particle bombardment, is a bombardment of the target tissues with high-density particles, like gold or tungsten, coated with plasmid DNA. The particles are accelerated to high velocity by an electrical discharge or compressed gas, usually helium, and then pass through cell membranes of the target cells (Uchida et al., 2009). Despite the limitation of the depth of penetration of plasmid DNA into the tissues, gene gun 
has been widely used for cutaneous gene therapy and immunization. To date, about $0.3 \%$ of all clinical trials in gene therapy using gene gun has been reported (Edelstein, 2012a).

\subsubsection{Electroporation}

The application of short and intense electric pulses to the tissues generates transient enhanced cell membranes permeability. Electroporation is conducted by a local or systemic administration of plasmid DNA into target tissues followed by an application of controlled electric pulses. This method has been reported to increase the levels of transgene expression up to 100- to 1,000- fold compared to the simple injection of plasmid DNA (Escoffre et al., 2010). The limitation of the method is the number of cell transfected and the invasive method is required for the accessibility of the electrodes to the internal organs (Kamimura et al., 2011).

Besides the physical approaches has been described above, various techniques has been developed such as jet injection (Escoffre et al., 2010), laser beam gene transduction(Escoffre et al., 2010), laser irradiation (Mehier-Humbert and Guy, 2005). The non-viral vector, which combined some physical approaches with synthetic vehicles such as sonoporation (Ultrasound-responsive vehicles) and magnetofection (magnetic field-responsive vehicles) have also been invented (Mehier-Humbert and Guy, 2005) for improved transfection efficiency.

\subsection{Chemical methods}

Chemical methods for non-viral gene delivery are based on the use of synthetic or natural substances. Electrostatic complex of the negative charged plasmid DNA with the positive charged molecules such as cationic lipids or cationic polymer are typical methods. 


\subsubsection{Liposome-based carriers}

Cationic lipid and plasmid DNA spontaneously form the complex via electrostatic interactions. The complex formation reduces the strong negative charge of plasmid DNA and facilitates its interaction with cell membrane, resulting in gene transfer into the cells.

Commonly used cationic lipids are N-[1-(2,3-dioleyloxy)propyl]-N,N,N-trimethylammonium chloride(DOTMA), [1,2-bis(oleoyloxy)-3-(trimethylammonio)propane] (DOTAP), and 3 $\beta[\mathrm{N}-$ $\left(\mathrm{N}^{\prime}, \mathrm{N}^{\prime}\right.$-dimethylaminoethane)-carbamoyl] cholesterol (DC-Chol). Although the net positive charge of the cationic lipid- plasmid DNA complex is preferred for lung-specific gene transfer, the cellular uptake of the cationic complex is non-specific. In order to improve the specificity of gene transfer, various types of liposome have been formulated using a variety of techniques and lipids, for example, anionic liposome, stealth liposome (Balazs and Godbey, 2011).

\subsubsection{Polymer-based carriers}

Cationic polymers have been also widely used for non-viral gene transfer. Numerous types of cationic polymers have been utilized for gene delivery, most common used polymers are polyethyleneimine (PEI), poly-L-lysine (PLL), chitosans and dendrimers (Patil et al., 2005). Transfection efficiency of polymeric based vehicles is based on many factors such as type of polymers used, net charge and size of particles. The physicochemical properties of vehicles determine the safety, efficiency and specificity of the strategy (Pack et al., 2005).

\section{Optimization of plasmid DNA components}

Unless the optimized plasmid delivery methods, the design of plasmid construct is the other key factor in achieving successful transgene expression. Two main components of plasmid DNA determine the extent of transgene expression as well as DNA production in bacteria. One is the gene control region, i.e., promoter and enhancer, which is required for regulating 
the transgene expression in eukaryotic cells. Another is the backbone of plasmid DNA, associated with the origin of replication and selection of marker genes, which are necessary for plasmid propagation in bacteria. The level and duration of transgene expression can be regulated by optimization of these plasmid components (Yew, 2005, van Gaal et al., 2006). Figure 1 demonstrates the schematics of the conventional plasmid and the modification of plasmid using various approaches.

\subsection{Promoter/enhancer selection}

The promoter is the key region for controlling the profile of transgene expression. Each promoter has a unique transgene expression profile. Therefore, selection of the optimal promoter, including other regulatory elements such as the enhancer, could control the kinetics of the transgene expression pattern of the plasmid. Various types of promoter with different expression characteristics have been reviewed (Yew, 2005). For example, CMV promoter, a widely used promoter that is derived from the regulation region of the immediate early gene of cytomegalovirus (CMV), exhibits transient expression. CMV promoter confers a strong expression of transgene but the level of transgene expression is rapidly reduced. Elongation factor $1 \alpha(\mathrm{EF} 1 \alpha)$ promoter is known to exert sustained gene expression although its expression level is lower than that of CMV promoter. Therefore, optimization of the promoter and enhancer combination is an effective way of obtaining high and sustained gene expression. As a good example of promoter optimization, Magnusson et al. optimized the promoter and enhancer for high and sustained transgene expression. Switching murine CMV (mCMV) enhancer to human CMV (hCMV) enhancer resulted in the sustained expression of luciferase (Luc) activity over 80 days, whereas the Luc expression of mCMV enhancerdriven plasmid DNA fell below the limit of detection in 45 days. This sustained transgene expression achieved with hCMV enhancer might be explained by the differences in type and 
number of transcription factors between species. Furthermore, to combine the high level of transgene expression from CMV promoter with the sustained expression profile of EF1 $\alpha$ promoter, the shuffle CMV-EF1 $\alpha$ promoter (SCEP) was engineered. The expression profile from SCEP was compared with that of standard promoter, including CMV promoter and EF1 $\alpha$ promoter with hCMV enhancer. CMV promoter showed a very transient expression profile compared with EF1 $\alpha$ promoter and SCEP. Both EF1 $\alpha$ promoter and SCEP showed a similar sustained expression profile. Furthermore, SCEP promoter showed a higher level of transgene expression than EF1 $\alpha$ promoter at all time points. This study demonstrated that a sustained transgene expression can be achieved by optimizing the promoter and enhancer compartment (Magnusson et al., 2011). 


\subsection{Modification of plasmid DNA backbone}

In addition to the promoter and enhancer, the plasmid DNA backbone should also be considered as it affects the profile of transgene expression.

\subsubsection{Depletion of CpG-motifs from plasmid DNA}

Although plasmid DNA is less immunogenic than viral vectors, the cytosine-phosphateguanine dinucleotides (CpG motifs) in plasmid DNA can induce inflammatory responses. The recognition of CpG motifs is mediated by Toll-like receptor 9 (TLR9), which consequently results in the generation of pro-inflammatory cytokines, such as tumor necrosis factor (TNF)- $\alpha$ and IFN- $\gamma$. Generally speaking, these cytokines have negative effects on transgene expression (Scheule, 2000). In addition, the methylation of cytosine residues of the CpG motif in plasmid DNA may also be related to transgene silencing (Scheule, 2000, Takahashi et al., 2012, Yew and Cheng, 2004). Therefore, the elimination of CpG motifs from plasmid DNA could reduce immune responses to the DNA and transgene silencing, resulting in the prolongation of transgene expression. Yew et al. constructed a plasmid DNA with a reduced number of $\mathrm{CpG}$ motifs (Yew et al., 2002). They named this plasmid vector pGZB vector. pGZB coding chloramphenicol acetyltransferase (CAT), pGZB-sCAT (containing $102 \mathrm{CpG}$ motifs), increased the duration of CAT expression in the lung and liver after in vivo gene transfer compared with ones consisting of conventional CpG-replete plasmid DNA (256 CpG motifs). Similar results were obtained when the CAT gene was replaced with blood coagulation factor IX. This study supported the hypothesis that persistent transgene expression is achieved by reducing the number of $\mathrm{CpG}$ motifs from plasmid DNA.

\subsubsection{Minicircle DNA}


Minicircle DNA, also known as a supercoiled minimal expression cassette, is an abridged form of conventional plasmid DNA obtained by eliminating all bacterial components, including a replication origin and an antibacterial resistant gene. Minicircle DNA contains only an expression cassette. including cDNA, enhancer and promoter (Mayrhofer et al., 2009). The initial concept of minicircle DNA is similar to CpG reduced plasmid DNA, namely, to avoid transgene silencing mediated by bacterial-derived sequences. Several studies have reported that more persistent transgene expression is obtained with minicircle DNA compared with their parenteral plasmid DNA (Chen et al., 2003, Wu et al., 2006, Argyros et al., 2011, Huang et al., 2009), even though the mechanism whereby bacterial sequences suppress transgene expression remains unclear. Chen et al. have obtained evidence that silencing of transgene expression was not merely affected by the $\mathrm{CpG}$ content or $\mathrm{CpG}$ methylation of DNA but was mediated by the covalent linkage of the plasmid backbone to the expression cassette (Chen et al., 2004, Riu et al., 2005). They suggested that the formation of repressive heterochromatin over the plasmid DNA backbone and its ability to spread out to the adjacent region might be involved in the transgene silencing (Chen et al., 2004, Chen et al., 2008). Furthermore, the latest report from the same group provided strong evidence that the length but not the sequence of the DNA insert between the 5' and 3' ends of transgene expression cassette is critical for transgene silencing (Lu et al., 2012). Moreover, several pieces of evidence have indicated an inverse correlation between plasmid size and transgene expression efficiency (Kreiss et al., 1999, Yin et al., 2005). Considering these observations, it seems that the reduced number of $\mathrm{CpG}$ contents is not the main factor responsible for the improved and persistent transgene expression from minicircle DNA over parenteral plasmid DNA. Instead, elimination of the plasmid bacterial backbone, shortening of the spacer between 5' and 3' ends of the transgene expression cassette and a reduction in plasmid size could be the reason for persistent transgene expression from minicircle DNA. 
3. Rational design of plasmid DNA encoding the IFN gene to control the kinetics of transgene expression

The development of IFN-based therapy has been hindered by the many disadvantages of IFN, such as its short in vivo half-life, which requires multiple and frequent administration. These increase patient-noncompliance and the cost. Gene delivery of IFN can be used to overcome these problems. As described above, a rational design of plasmid DNA encoding the IFN gene is effective in optimizing IFN transgene expression. This section reviews the application of the strategies to IFN expressing plasmid DNA.

\subsection{Improved duration of IFN transgene expression by using $\mathrm{CpG}$ reduced plasmid DNA} As already described, removal of CpG motifs from plasmid DNA generally results in the prolongation of transgene expression. We have demonstrated that prolonged expression of IFN- $\beta$ and IFN- $\gamma$ was obtained by using $\mathrm{CpG}$ reduced pGZB vector. A single hydrodynamic injection of pGZB vector encoding murine IFN- $\beta$ (pGZB-Mu $\beta$ ) into mice resulted in more sustained expression of IFN- $\beta$ compared with CpG-replete pCMV-Mu $\beta$. Moreover, the inhibitory effect of IFN- $\beta$ gene transfer on pulmonary metastasis of CT-26 carcinoma cells was high in mice receiving pGZB-Mu $\beta$ compared with that in those receiving $\mathrm{pCMV}-\mathrm{Mu} \beta$. Similar results were obtained with plasmids expressing murine IFN- $\gamma$. These results indicate that the removal of CpG motifs from plasmid DNA enhances the therapeutic effects of IFN gene transfer through prolongation of IFN transgene expression (Kawano et al., 2007). In order to further reduce the number of $\mathrm{CpG}$ motifs in plasmid DNA, CpG-free plasmid vector, called pCpG plasmid (Invivogen), which has no CpG motifs, was chosen to construct plasmid DNA encoding murine IFN- $\gamma$ (pCpG-Mu $\gamma$ ). As expected, administration of pCpG- 
Mu $\gamma$ resulted in more sustained IFN- $\gamma$ expression and a greater anti-tumor effect compared

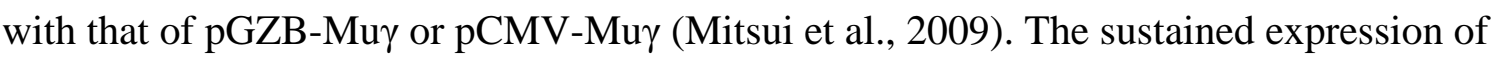
IFN- $\gamma$ from $\mathrm{pCpG-Mu} \gamma$ was also beneficial in treating chronic diseases, like atopic dermatitis. We succeeded in ameliorating the development of Th2 dominant atopic dermatitis in NC/Nga mice, a mouse model of atopic dermatitis (Hattori et al., 2010). The sustained IFN- $\gamma$ expression in mice shifted the immunological balance toward Th1. This effect was not observed in mice receiving multiple injections of pCMV-Mur. Therefore, we proposed CpG depleted plasmid DNA encoding IFN- $\gamma$, pCpG-Mu $\gamma$ as a useful method for IFN- $\gamma$ gene therapy.

\subsection{Combination of $\mathrm{CpG}$ reduction and selection of promoter/enhancer}

$\mathrm{CpG}$ reduced plasmid DNA encoding murine IFN- $\gamma$ provided high and sustained transgene expression of IFN- $\gamma$ in mice after hydrodynamic injection and produced potent therapeutic effects on tumor growth or atopic dermatitis (Mitsui et al., 2009, Hattori et al., 2010). However, the administration of pCpG-Mu $\gamma$ was associated with very high concentrations of IFN- $\gamma$ soon after gene transfer, which fell with time to a constant, steady level. The high initial concentrations of IFN $\gamma$ could induce unwanted responses, such as body weight loss. The plasmid pCpG-Mur contains human elongation factor (hEF)-1 promoter and murine cytomegalovirus (mCMV) enhancer. The hydrodynamic injection method, which was used for gene transfer in the study of plasmid $\mathrm{pCpG-Mu \gamma ,} \mathrm{has} \mathrm{been} \mathrm{reported} \mathrm{to} \mathrm{activate}$

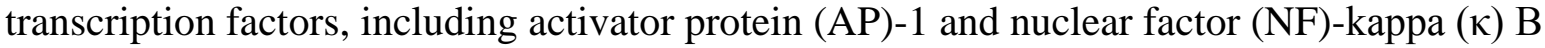
in the liver (Nishikawa et al., 2008). As mCMV enhancer contains many binding sites for AP-1 and NF- $\kappa \mathrm{B}$, the activation of transcription factors by hydrodynamic injection could result in an initial surge in transgene expression. We designed and constructed a plasmid vector that exhibits a constant and steady expression of IFN- $\gamma$ for minimizing the adverse 
effects caused by initial high concentrations of IFN- $\gamma$ (Ando et al., 2012). As the kinetics of transgene expression is mainly governed by the type of promoter and enhancer, we constructed a series of plasmid vectors with different promoters and enhancers. As a result, we found that the plasmid DNA containing human ROSA26 (hROSA26) promoter produced a constant and steady expression of IFN- $\gamma$. Furthermore, adverse effects, such as body weight loss, which was observed in mice receiving a high dose pCpG-Mur, were not observed in mice receiving hROSA promoter-driven IFN $\gamma$-expressing plasmid DNA. Lack of binding sites for AP-1 and NF- $\mathrm{KB}$ in the hROSA26 promoter seems to be responsible for the constant transgene expression. Interestingly, the duration of IFN- $\gamma$ transgene expression from hROSA26 promoter-containing plasmid DNA was comparable with that from $\mathrm{pCpG}$ plasmid, despite the fact that the hROSA26 promoter contains as many as $428 \mathrm{CpG}$ motifs. As the hROSA26 promoter contains many binding sites for SP1, a steady transcription factor, sustained transgene expression from hROSA26 promoter might be due to its many SP-1 binding sites. The reason why sustained transgene expression is obtained by using the $\mathrm{CpG}$ replete hROSA26 promoter-driven plasmid DNA has not been identified yet. However, these results suggest that the number of $\mathrm{CpG}$ motifs in plasmid DNA is not a major factor controlling the profile of transgene expression.

3.3 Minicircle DNA with a tumor-selective promoter as a tumor- specific expression system Minicircle DNA is attractive for persistent transgene expression. Wu et al. applied this DNA to IFN- $\gamma$ gene therapy of cancer. The anti-tumor effects of IFN- $\gamma$ on human nasopharyngeal carcinoma (NPC) were studied by using minicircle-mediated IFN- $\gamma$ gene transfer. IFN- $\gamma$ gene transfer by minicircle DNA exhibited better antiproliferative effects in NPC tumor-bearing mice than those obtained by its plasmid DNA counterpart, which was a consequence of a high and persistent transgene expression of IFN- $\gamma$ from the minicircle DNA (Wu et al., 2006). 
As a close correlation between the pathogenesis of NPC and EBV infection has been reported (Raab-Traub, 2002), oriP promoter, which contains many binding sites for EBV nuclear antigen 1 (EBNA-1), was used for minicircle DNA encoding IFN- $\gamma$ to increase the specificity of transgene expression in NPC tumors (Yates et al., 2000). The results obtained showed that minicircle DNA, the IFN- $\gamma$ expression of which was driven by the oriP promoter, had no antitumor effects on EBV-negative tumor xenografts but produced tumor regression and prolonged survival in EBV positive tumor-bearing mice. Moreover, the IFN- $\gamma$ level in the liver was significantly lower in mice receiving oriP promoter-based minicircle DNA than that in those receiving CMV promoter-based minicircle DNA. These findings suggest that the oriP promoter-based IFN- $\gamma$-expressing minicircle DNA can be used as a safe and effective therapy to treat EBV positive NPC (Zuo et al., 2011).

3.4 Small molecule-inducible plasmid DNA for long-term and renewable transgene expression

Drug-regulated transgene expression systems have been established to manipulate spatial and temporal aspects of transgene expression. Generally, this plasmid system consists of two key components. The first component expresses an inactive form of a regulatory protein, which will be activated after binding of a small-molecule inducer. The other one carries the transgene of interest, which is expressed in response to the activation of the regulatory protein (Nordstrom, 2003). A mifepristone (MFP)-inducible plasmid system, termed pBRES has been constructed by Szymanski et al. A variety of trangenes, including human IFN $\beta$, were inserted into the pBRES plasmid and the regulation of transgene expression in response to MFP was examined. For example, the intraperitoneal injection of MFP following the transfection of pBRES plasmid encoding human IFN $\beta$ (pBRES-hIFN $\beta$ ) into murine hind 
limb muscles with electroporation resulted in detectable serum levels of hIFN $\beta$ while, in the absence of MFP, the level of hIFN $\beta$ in mouse serum was undetectable (Szymanski et al., 2007). Harkins et al. applied the pBRES plasmid system for encoding murine IFN- $\beta$ and investigated the therapeutic effect in a murine model of experimental allergic encephalomyelitis (EAE). This plasmid DNA induced efficient and sustained expression of interferon-inducible protein-10, which is used as a marker of IFN activity, in mice for up to 3 months under MFP induction. Repeated administration of plasmid resulted in renewed expression. The administration of the pBRES murine IFN $\beta$ plasmid with an inducer MFP produced an efficient therapeutic effect compared with the control plasmid or pBRES murine IFN- $\beta$ plasmid administration without MFP in a mouse model of EAE (Harkins et al., 2008). 


\section{Conclusions}

IFN gene transfer could avoid the many drawbacks of IFN-based therapy and a number of clinical trials have been conducted using IFN gene transfer (Kalanjeri and Sterman, 2012). However, most of these studies use viral vectors. Only few studies use non-viral vector, which is cationic liposome (Wakabayashi et al., 2008, Matsumoto et al., 2008). In order to expand the range of IFN gene therapy by plasmid DNA vector, an engineered plasmid DNA vector that can regulate spatio-temporal distribution of IFN is required. In the present review, we have summarized attractive strategies that can be used to obtain more precisely controlled transgene expression of IFN using the modified plasmid DNA via simple administration methods such as hydrodynamic injection (Ando et al., 2012, Hattori et al., 2010, Mitsui et al., 2009), intratumoral injection of plasmid-liposome complex (Wu et al., 2006, Zuo et al., 2011) and intramuscular injection (Harkins et al., 2008). Using plasmid modification techniques described in the present review is a promising strategy for improving the therapeutic efficacy and safety profile of IFN gene therapy. 
Declaration of interest: The authors report no conflicts of interest. 
References. [Accessed 16 May 20122012 ].

. Available: http://www.invivogen.com/PDF/pCpGfree-mcs_TDS_09D27MM.pdf [Accessed May 16 2012].

AL-DOSARI, M. S. \& GAO, X. 2009. Nonviral gene delivery: principle, limitations, and recent progress. AAPS J, 11, 671-81.

ANDO, M., TAKAHASHI, Y., NISHIKAWA, M., WATANABE, Y.\& TAKAKURA, Y. 2012. Constant and steady transgene expression of interferon- $\gamma$ by optimization of plasmid construct for safe and effective interferon- $\gamma$ gene therapy. J Gene Med, 14, 288-95.

ARGYROS, O., WONG, S. P., FEDONIDIS, C., TOLMACHOV, O., WADDINGTON, S. N., HOWE, S. J., NICETA, M., COUTELLE, C. \& HARBOTTLE, R. P. 2011. Development of S/MAR minicircles for enhanced and persistent transgene expression in the mouse liver. J Mol Med (Berl), 89, 515-29.

BALAZS, D. A. \& GODBEY, W. 2011. Liposomes for use in gene delivery. J Drug Deliv, $2011,326497$.

BRACARDA, S., EGGERMONT, A. M. \& SAMUELSSON, J. 2010. Redefining the role of interferon in the treatment of malignant diseases. Eur J Cancer, 46, 284-97.

CHEN, Z. Y., HE, C. Y., EHRHARDT, A. \& KAY, M. A. 2003. Minicircle DNA vectors devoid of bacterial DNA result in persistent and high-level transgene expression in vivo. Mol Ther, 8, 495-500.

CHEN, Z. Y., HE, C. Y., MEUSE, L. \& KAY, M. A. 2004. Silencing of episomal transgene expression by plasmid bacterial DNA elements in vivo. Gene Ther, 11, 856-64.

CHEN, Z. Y., RIU, E., HE, C. Y., XU, H. \& KAY, M. A. 2008. Silencing of episomal transgene expression in liver by plasmid bacterial backbone DNA is independent of CpG methylation. Mol Ther, 16, 548-56.

CHOATE, K. A. \& KHAVARI, P. A. 1997. Direct cutaneous gene delivery in a human genetic skin disease. Hum Gene Ther, 8, 1659-65.

EASTMAN, S. J., BASKIN, K. M., HODGES, B. L., CHU, Q., GATES, A., DREUSICKE, R., ANDERSON, S. \& SCHEULE, R. K. 2002. Development of catheter-based procedures for transducing the isolated rabbit liver with plasmid DNA. Hum Gene Ther, 13, 2065-77.

EDELSTEIN, M. 2012a. Gene therapy clinical trials worldwide [Online]. John Wiley and Sons Ltd. Available: http://www.wiley.com/legacy/wileychi/genmed/clinical/ [Accessed 24 April 2012].

EDELSTEIN, M. 2012b. Gene therapy clinical trials worldwide [Online]. John Wiley and Sons Ltd. Available: http://www.wiley.com/legacy/wileychi/genmed/clinical/ [Accessed 24 April 2012 2012].

EDELSTEIN, M. L., ABEDI, M. R. \& WIXON, J. 2007. Gene therapy clinical trials worldwide to 2007--an update. J Gene Med, 9, 833-42.

EDELSTEIN, M. L., ABEDI, M. R., WIXON, J. \& EDELSTEIN, R. M. 2004. Gene therapy clinical trials worldwide 1989-2004-an overview. J Gene Med, 6, 597-602.

ESCOFFRE, J. M., TEISSIÉ, J. \& ROLS, M. P. 2010. Gene transfer: how can the biological barriers be overcome? J Membr Biol, 236, 61-74.

HARKINS, R. N., SZYMANSKI, P., PETRY, H., BROOKS, A., QIAN, H. S., SCHAEFER, C., KRETSCHMER, P. J., ORME, A., WANG, P., RUBANYI, G. M. \& HERMISTON, T. W. 2008. Regulated expression of the interferon-beta gene in mice. Gene Ther, 15, 1-11.

HATTORI, K., NISHIKAWA, M., WATCHARANURAK, K., IKOMA, A., KABASHIMA, K., TOYOTA, H., TAKAHASHI, Y., TAKAHASHI, R., WATANABE, Y. \& TAKAKURA, Y. 2010. Sustained exogenous expression of therapeutic levels of IFN- 
gamma ameliorates atopic dermatitis in NC/Nga mice via Th1 polarization. $J$ Immunol, 184, 2729-35.

HUANG, M., CHEN, Z., HU, S., JIA, F., LI, Z., HOYT, G., ROBBINS, R. C., KAY, M. A. $\&$ WU, J. C. 2009. Novel minicircle vector for gene therapy in murine myocardial infarction. Circulation, 120, S230-7.

HUGHES, T. S., LANGER, S. J., JOHNSON, K. W., CHAVEZ, R. A., WATKINS, L. R., MILLIGAN, E. D. \& LEINWAND, L. A. 2009. Intrathecal injection of naked plasmid DNA provides long-term expression of secreted proteins. Mol Ther, 17, 8894.

KALANJERI, S. \& STERMAN, D. 2012. Gene therapy in interventional pulmonology: Interferon gene delivery with focus on thoracic malignancies. Current Respiratory Care Reports, 1, 54-66.

KAMIMURA, K., SUDA, T., ZHANG, G. \& LIU, D. 2011. Advances in Gene Delivery Systems. Pharmaceut Med, 25, 293-306.

KAWANO, H., NISHIKAWA, M., MITSUI, M., TAKAHASHI, Y., KAKO, K., YAMAOKA, K., WATANABE, Y. \& TAKAKURA, Y. 2007. Improved anti-cancer effect of interferon gene transfer by sustained expression using CpG-reduced plasmid DNA. Int J Cancer, 121, 401-6.

KAY, M. A. 2011. State-of-the-art gene-based therapies: the road ahead. Nat Rev Genet, 12, 316-28.

KREISS, P., CAMERON, B., RANGARA, R., MAILHE, P., AGUERRE-CHARRIOL, O., AIRIAU, M., SCHERMAN, D., CROUZET, J. \& PITARD, B. 1999. Plasmid DNA size does not affect the physicochemical properties of lipoplexes but modulates gene transfer efficiency. Nucleic Acids Res, 27, 3792-8.

LI, S. D. \& HUANG, L. 2007. Non-viral is superior to viral gene delivery. J Control Release, 123, 181-3.

LU, J., ZHANG, F., XU, S., FIRE, A. Z. \& KAY, M. A. 2012. The Extragenic Spacer Length Between the 5' and 3' Ends of the Transgene Expression Cassette Affects Transgene Silencing From Plasmid-based Vectors. Mol Ther.

MAGNUSSON, T., HAASE, R., SCHLEEF, M., WAGNER, E. \& OGRIS, M. 2011.

Sustained, high transgene expression in liver with plasmid vectors using optimized promoter-enhancer combinations. J Gene Med, 13, 382-91.

MATSUMOTO, K., KUBO, H., MURATA, H., UHARA, H., TAKATA, M., SHIBATA, S., YASUE, S., SAKAKIBARA, A., TOMITA, Y., KAGESHITA, T., KAWAKAMI, Y., MIZUNO, M., YOSHIDA, J. \& SAIDA, T. 2008. A pilot study of human interferon beta gene therapy for patients with advanced melanoma by in vivo transduction using cationic liposomes. Jpn J Clin Oncol, 38, 849-56.

MAYRHOFER, P., SCHLEEF, M. \& JECHLINGER, W. 2009. Use of minicircle plasmids for gene therapy. Methods Mol Biol, 542, 87-104.

MEHIER-HUMBERT, S. \& GUY, R. H. 2005. Physical methods for gene transfer: improving the kinetics of gene delivery into cells. Adv Drug Deliv Rev, 57, 733-53.

MITSUI, M., NISHIKAWA, M., ZANG, L., ANDO, M., HATTORI, K., TAKAHASHI, Y., WATANABE, Y. \& TAKAKURA, Y. 2009. Effect of the content of unmethylated CpG dinucleotides in plasmid DNA on the sustainability of transgene expression. $J$ Gene Med, 11, 435-43.

NISHIKAWA, M. \& HASHIDA, M. 2002. Nonviral approaches satisfying various requirements for effective in vivo gene therapy. Biol Pharm Bull, 25, 275-83.

NISHIKAWA, M. \& HUANG, L. 2001. Nonviral vectors in the new millennium: delivery barriers in gene transfer. Hum Gene Ther, 12, 861-70. 
NISHIKAWA, M., NAKAYAMA, A., TAKAHASHI, Y., FUKUHARA, Y. \& TAKAKURA, Y. 2008. Reactivation of silenced transgene expression in mouse liver by rapid, largevolume injection of isotonic solution. Hum Gene Ther, 19, 1009-20.

NOMURA, T., NAKAJIMA, S., KAWABATA, K., YAMASHITA, F., TAKAKURA, Y. \& HASHIDA, M. 1997. Intratumoral pharmacokinetics and in vivo gene expression of naked plasmid DNA and its cationic liposome complexes after direct gene transfer. Cancer Res, 57, 2681-6.

NORDSTROM, J. L. 2003. The antiprogestin-dependent GeneSwitch system for regulated gene therapy. Steroids, 68, 1085-94.

PACK, D. W., HOFFMAN, A. S., PUN, S. \& STAYTON, P. S. 2005. Design and development of polymers for gene delivery. Nat Rev Drug Discov, 4, 581-93.

PATIL, S. D., RHODES, D. G. \& BURGESS, D. J. 2005. DNA-based therapeutics and DNA delivery systems: a comprehensive review. AAPS J, 7, E61-77.

PLATANIAS, L. C. 2005. Mechanisms of type-I- and type-II-interferon-mediated signalling. Nat Rev Immunol, 5, 375-86.

RAAB-TRAUB, N. 2002. Epstein-Barr virus in the pathogenesis of NPC. Semin Cancer Biol, $12,431-41$.

RIU, E., GRIMM, D., HUANG, Z. \& KAY, M. A. 2005. Increased maintenance and persistence of transgenes by excision of expression cassettes from plasmid sequences in vivo. Hum Gene Ther, 16, 558-70.

SADLER, A. J. \& WILLIAMS, B. R. 2008. Interferon-inducible antiviral effectors. Nat Rev Immunol, 8, 559-68.

SCHEULE, R. K. 2000. The role of CpG motifs in immunostimulation and gene therapy. Adv Drug Deliv Rev, 44, 119-34.

SUDA, T., SUDA, K. \& LIU, D. 2008. Computer-assisted hydrodynamic gene delivery. Mol Ther, 16, 1098-104.

SZYMANSKI, P., KRETSCHMER, P. J., BAUZON, M., JIN, F., QIAN, H. S., RUBANYI, G. M., HARKINS, R. N. \& HERMISTON, T. W. 2007. Development and validation of a robust and versatile one-plasmid regulated gene expression system. Mol Ther, 15, 1340-7.

TAKAHASHI, Y., NISHIKAWA, M. \& TAKAKURA, Y. 2012. Development of safe and effective nonviral gene therapy by eliminating CpG motifs from plasmid DNA vector. Front Biosci (Schol Ed), 4, 133-41.

UCHIDA, M., LI, X. W., MERTENS, P. \& ALPAR, H. O. 2009. Transfection by particle bombardment: delivery of plasmid DNA into mammalian cells using gene gun. Biochim Biophys Acta, 1790, 754-64.

VAN GAAL, E. V., HENNINK, W. E., CROMMELIN, D. J. \& MASTROBATTISTA, E. 2006. Plasmid engineering for controlled and sustained gene expression for nonviral gene therapy. Pharm Res, 23, 1053-74.

WAKABAYASHI, T., NATSUME, A., HASHIZUME, Y., FUJI, M., MIZUNO, M. \& YOSHIDA, J. 2008. A phase I clinical trial of interferon-beta gene therapy for highgrade glioma: novel findings from gene expression profiling and autopsy. J Gene Med, 10, 329-39.

WOLFF, J. A., MALONE, R. W., WILLIAMS, P., CHONG, W., ACSADI, G., JANI, A. \& FELGNER, P. L. 1990. Direct gene transfer into mouse muscle in vivo. Science, 247, 1465-8.

WU, J., XIAO, X., ZHAO, P., XUE, G., ZHU, Y., ZHU, X., ZHENG, L., ZENG, Y. \& HUANG, W. 2006. Minicircle-IFNgamma induces antiproliferative and antitumoral effects in human nasopharyngeal carcinoma. Clin Cancer Res, 12, 4702-13. 
YATES, J. L., CAMIOLO, S. M. \& BASHAW, J. M. 2000. The minimal replicator of Epstein-Barr virus oriP. $J$ Virol, 74, 4512-22.

YEW, N. S. 2005. Controlling the kinetics of transgene expression by plasmid design. $A d v$ Drug Deliv Rev, 57, 769-80.

YEW, N. S. \& CHENG, S. H. 2004. Reducing the immunostimulatory activity of CpGcontaining plasmid DNA vectors for non-viral gene therapy. Expert Opin Drug Deliv, $1,115-25$.

YEW, N. S., ZHAO, H., PRZYBYLSKA, M., WU, I. H., TOUSIGNANT, J. D., SCHEULE, R. K. \& CHENG, S. H. 2002. CpG-depleted plasmid DNA vectors with enhanced safety and long-term gene expression in vivo. Mol Ther, 5, 731-8.

YIN, W., XIANG, P. \& LI, Q. 2005. Investigations of the effect of DNA size in transient transfection assay using dual luciferase system. Anal Biochem, 346, 289-94.

ZHANG, G., GAO, X., SONG, Y. K., VOLLMER, R., STOLZ, D. B., GASIOROWSKI, J. Z., DEAN, D. A. \& LIU, D. 2004. Hydroporation as the mechanism of hydrodynamic delivery. Gene Ther, 11, 675-82.

ZUO, Y., WU, J., XU, Z., YANG, S., YAN, H., TAN, L., MENG, X., YING, X., LIU, R., KANG, T. \& HUANG, W. 2011. Minicircle-oriP-IFN $\gamma$ : a novel targeted gene therapeutic system for EBV positive human nasopharyngeal carcinoma. PLoS One, 6, e19407. 


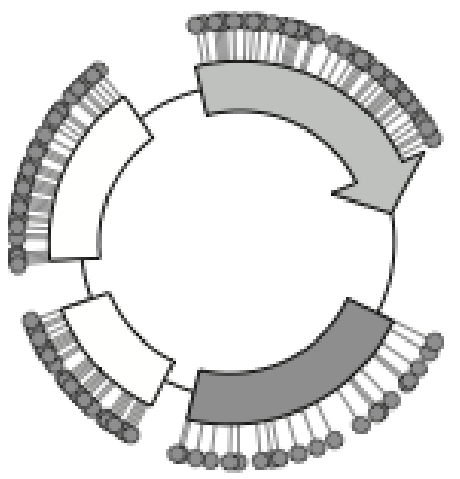

a) Promoter/ enhancer switching

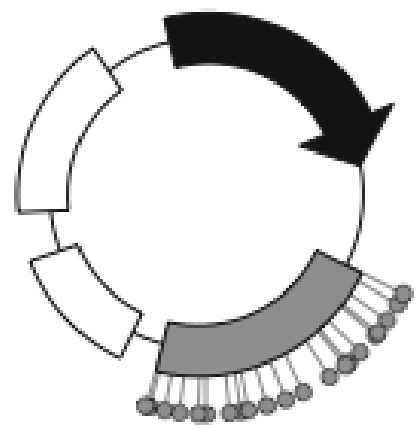

b) CpG moitfs depletion

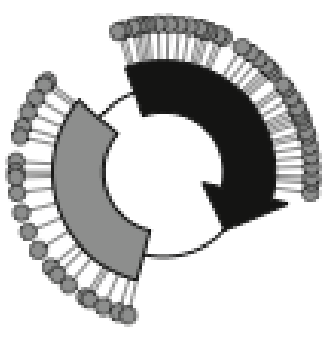

c) Minicircle DNA

Figure 1. Schematics of conventional (unmodified) plasmid DNA (top image) and the modifications of plasmid DNA for controlling the kinetics of transgene expression: (a) promoter/ enhancer selection, (b) depletion of CpG motifs from plasmid DNA and (c) elimination of plasmid bacterial backbone (minicircle DNA). 